\title{
Influence of Acid Etching on Bond Strength Between Feldspathic Ceramics and Resin Cement
}

\author{
Ricardo Huver de Jesus, ${ }^{1}$ Bianca Colombi Furlam, ${ }^{2}$ Camila Maciel Martinusse, ${ }^{2}$ Hiorrana Carla Vasconcelos Inácio, ${ }^{2}$ Jefferson David Melo de Matos, ${ }^{3}$ Leonardo \\ Jiro Nomura Nakano, ${ }^{3}$ Laura Patricia Nadal Ortiz, ${ }^{3}$ Marco Antonio Bottino, ${ }^{3}$ Lucas Campagnaro Maciel ${ }^{1}$ \\ ${ }^{1}$ Department of Dentistry, School of Dentistry of Multivix, Multivix College, Vitória, ES, Brazil \\ ${ }^{2}$ Department of Dentistry, Escola Superior São Francisco de Assis (ESFA), Santa Teresa, ES, Brazil \\ ${ }^{3}$ Department of Dental Materials and Prosthodontics, Institute of Science and Technology, São Paulo State University (Unesp), São José dos Campos, SP, Brazil \\ - Conflicts of interest: none declared.
}

\section{Abstract}

Objective: analyze the influence of bond strength between resin cement and feldspathic ceramics using different concentrations and application times of hydrofluoric acid (HF). Materials and Methods: 18 feldspathic ceramic discs $(\varnothing 10 \mathrm{~mm}-2 \mathrm{~mm}$ thickness) were made through the incremental technique, which were included in acrylic resin and regularized with silicon carbide sandpaper with granulations of 600, 1200 and 2000 through a polishing machine with a speed of 600 rpm. Soon after, they were immersed in distilled water for 10 minutes in an ultrasonic bath. All specimens were conditioned with $\mathrm{HF}$ and silanized. Four cement cylinders were made on each specimen ( $n=12)$, manufactured with Relyx ARC resin cement. After that, it was divided into six groups according to the surface treatment protocol: $\mathrm{G} 1$ ( $5 \%$ - $40 \mathrm{~s})$; G2 (5\% - 60s); G3 (5\% - 80s); G4 (10\% - 40s); G5 (10\% - 60s) e G6 (10\% - 80s). The specimens were subjected to the Microshear Test, with vertical force at a speed of 0.5 $\mathrm{mm}$ min on the specimen. The microshear bond strength was calculated and expressed in Megapascal (MPa). The data were submitted to two-way analysis of variance (ANOVA) and Tukey's test for multiple comparisons, with a significance level of $5 \%$. Results: when the concentration of HF was analyzed, there were no statistical differences ( $p>0.05)$. In the comparison of application times, G3 (5\% - 80s) and G6 (10\% - 80s) obtained higher results of microshear resistance than the other groups. Conclusion: The different concentrations of HF did not influence the bond strength between feldspathic ceramics and resin cement. However, the increase in the time of HF conditioning affected in the bond strength.

Keywords: Ceramics; Resin Cements; Fluoridric Acid.

\section{Introduction}

$\mathrm{C}$ urrently, dental ceramics are the restorative materials with the best optical properties ${ }^{1}$. They have favorable properties and become able to resemble the dental element, offering a more natural treatment to the patient. ${ }^{2}$ Other properties are desirable for this material as well, including chemical stability, compression resistance, biocompatibility and thermal expansion coefficient similar to dental structure. ${ }^{3}$

Campos et al. ${ }^{4}$ shows that, despite the numerous advantages of dental ceramics, there are some disadvantages, such as: friable and fragile material when subjected to traction. Therefore, the search to reduce failures has led to research to obtain a more resistant material, as well as surface treatments, to improve the union of ceramics and cement. ${ }^{5}$

It is not only the resistance of the interior of the prosthetic restoration that is relevant, the success of prosthetic rehabilitations with metal-free ceramics depends on numerous factors, including the cementing technique. This phase covers two bonding interfaces (dentin or enamel/cement and ceramic/cement). ${ }^{6}$ The adhesion of conventional resin cement to the dental element is improved when acid etching is used in enamel and dentin followed by hybridization. Likewise, ceramics should also be prepared to improve micromechanical retention to cement. ${ }^{7}$

Ceramics can be classified as vitreous ceramics, polycrystalline ceramics and hybrid ceramics. Just as there are different compositions of ceramics and bonding agents, there are also some surface treatment protocols that differ according to the choice of these materials. ${ }^{8}$ Vitreous ceramics have a high silica content and have an excellent aesthetic performance (feldspathic ceramics, leucite and lithium disilicate), therefore, the surface treatment of choice for this type of ceramic is conditioning with $10 \%$ hydrofluoric acid (HF), followed by application of silane and a bonding agent, which is cement. This protocol is capable of producing good results. ${ }^{9}$

The absence of conditioning with hydrofluoric acid on the ceramic surface can reduce the bond strength of the material with the cement. Poor bonding quality at the cement/ceramic interface can decrease the ability of a ceramic to resist the beginning of a fracture. ${ }^{10}$

Most failures occurred in pure ceramic prostheses are caused by the bonding interface or internal ceramic surfaces. It is necessary to reduce marginal infiltration, improve retention and fracture resistance of fixed prostheses and identify a safe conditioning technique for the internal surface of ceramic systems available for cementation. ${ }^{11}$

The aim of this study was to analyze the influence of different conditioning protocols of feldspathic ceramics with hydrofluoric acid on the bond strength of the interface between resin cement and restorative material. 


\section{Study Design}

This study was an experimental research in which the factor under study was the time of acid application (in three levels) and the concentration of acid (in two levels). Having as a variable of response the microshear bond strength measured and expressed in Megapascal (MPa) of quantitative nature.

\section{Specimen Preparation}

Through the incremental technique, 18 discs (Figure 1) of feldspathic ceramics (Super porcelain EX-3, Noritake, Japan) were manufactured in the dimensions ( $\varnothing 10 \mathrm{~mm}-2 \mathrm{~mm}$ thick). The sintering process was done in a ceramic oven (Futura Brasil Premium Press, SP, BR) and temperature application according to the manufacturer's recommendations. The ceramic discs were embedded in a colorless, chemically activated acrylic resin (Articles Dental Classic, São Paulo, SP, Brazil) using a condensation silicone matrix (Speedex Putty Condensation Silicone, Coltene, Rio de Janeiro, RJ, BR) in a square format. All specimens were regularized with silicon carbide sandpaper (Silicon Carbide, 3M from Brazil, Sumaré, SP, BR) with granulations of 600,1200 and 2000 through a polishing machine (Politriz PLO2E metallographic sander, Teclago, Vargem Grande Paulista, SP, BR) with a 600 rpm speed. Soon after they were immersed in distilled water for 10 minutes in ultrasonic bath (Soni Clean 6, Sanders do Brasil, Santa Rita de Sapucaí, MG, BR).

Figure 1. Specimen in ceramic disc format.

Hydrofluoric acid (Condporcelana, Dentscare LTDA FGM, Joinville, SC, BR) was used at concentrations of $5 \%$ and $10 \%$ and arranged for different conditioning times of 40,60 and 80 seconds on the ceramic surface. The specimens were randomly separated and divided into six groups according to the surface treatment protocol: Group 1 (G1), 5\% hydrofluoric acid was used for 40 seconds; Group 2 (G2), 5\% hydrofluoric acid for 60 seconds; Group 3 (G3), 5\% hydrofluoric acid for 80 seconds; Group 4 (G4), 10\% hydrofluoric acid for 40 seconds;
Group 5 (G5), 10\% hydrofluoric acid for 60 seconds and Group 6 (G6), 10\% hydrofluoric acid for 80 seconds. Right after, the washing was carried out under running water for 1 minute and the specimens were dried, a thin layer of silane agent was applied (Angelus Indústria de Produtos Odontológicas S/A, Londrina, PR, BR), and dried air after 1 minute.

On each ceramic disc, 4 cylinders of resin cement (Ø1.0 $\mathrm{mm}$ ) were manufactured, using tubes for peristaltic pump (Tygon E-laboratory, Materflex, Vernon Hills, IL, USA) of 1.0 $\mathrm{mm}$ internal diameter and $1.0 \mathrm{~mm}$ high. The resin cement used to make the cylinders was the dual-cured resin cement (Relyx ARC, 3M ESPE, St Paul, MN, USA). The cementation protocol was standardized for the six groups. In making the cement tubes over the ceramic specimens, the cement used was spatulated on paper mixing pad with a spatula number 24 (Quinelato, Rio Claro, SP, BR) for 20 seconds. After manipulation, the cement was deposited inside the tube with a centrix syringe (Makeup Dental Products Industry S.A., Maringá, PR, BR) and insertion tips. Then, the tubes were placed on the ceramic blocks surface and photopolymerized (Bluephase N Polymerizer, Ivoclar Vivadent, Barueri, SP, BR) with light intensity of $1,200 \mathrm{~mW} / \mathrm{cm} 2$ for 20 seconds.

\section{Microshear Test}

All specimens presented were submitted to the microshear test (Figure 2), which was performed on a universal testing machine (EMIC DL-2000, São José dos Pinhais, PR, BR). A $10 \mathrm{~cm}$ high prefabricated vertical rod was used, with a 10 $\mathrm{mm}$ wide bevel-shaped tip. Then it was positioned as close as possible to the tested interface, making a vertical downward force on the fixed part to the base of the equipment. The micro-shear stress was applied at a speed of $0.5 \mathrm{~mm} / \mathrm{min}$ until the failure of the resin cement cylinders. The bond strength to the micro shear was calculated and expressed in Megapascal (MPa).

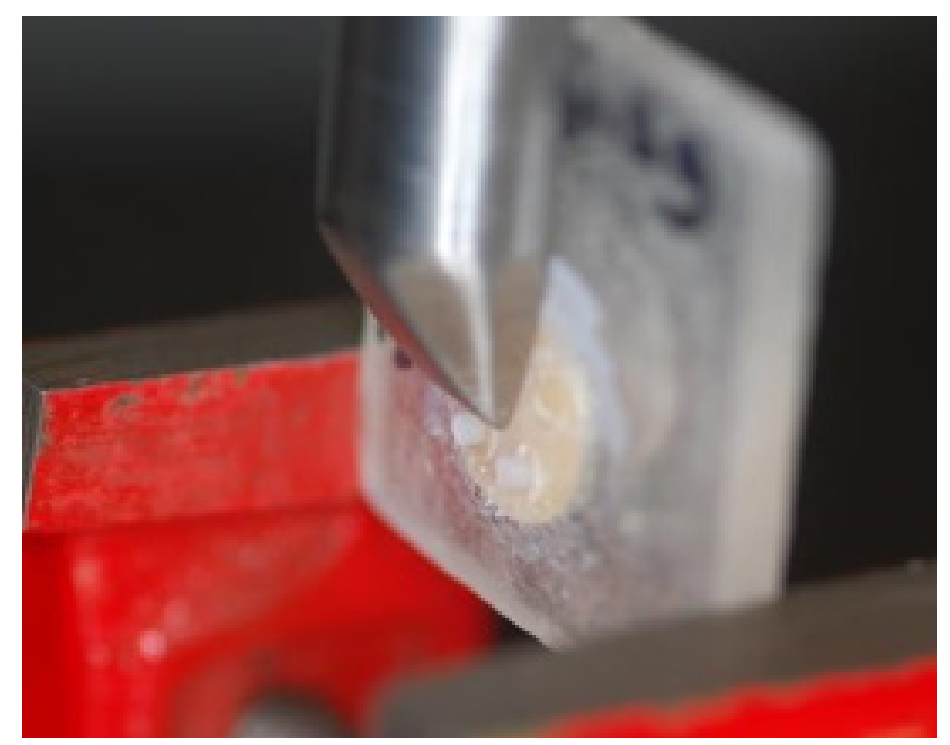

Figure 2. Microshear test. 


\section{Failure mode check}

After the micro shear tests, all specimens were checked with a stereoscopic magnifying glass (Aus Jena, Carl Zaiss, BW, DE) with a 40x magnification failure detection. The patterns were divided into: adhesive failure, when the rupture occurs at the interface between cement and ceramic; cohesive failure, when the rupture occurs in the restorative material (cement or ceramic); mixed failure, when the rupture occurs, part of the restorative material (cement or ceramic) and part of the cement/ceramic interface.

\section{Statistical Analysis}

The data were submitted to descriptive analysis and evaluated for compliance with the requirements of normality and homogeneity of variance. The aspects were met and the data were submitted to two-way analysis of variance (ANOVA), for multiple comparisons the Tukey test was used, at the significance level nível $p=0.05$.

\section{Results}

The results of the microshear testing are described in Table 1. When the variable concentration of hydrofluoric acid was tested, no statistical differences were observed for each application time ( $p>0.05)$. When comparing the application times, G3 obtained higher microshear resistance results than G1 and G2 $(p<0.05)$ for a concentration of $5 \%$. Likewise, G6 obtained higher resistance than G4 and G5 $(p<0.001)$ when the concentration was $10 \%$.

Table 1. Microshear bond strength (Means $(\mathrm{MPa}) \pm$ standard deviation).

\begin{tabular}{l|c|c}
\hline & $\begin{array}{c}\text { Hydrofluoric Acid } \\
5 \%\end{array}$ & $\begin{array}{c}\text { Hydrofluoric Acid } \\
10 \%\end{array}$ \\
\hline 40 seconds & $9.32 \pm 1,54^{\mathrm{Bc}}$ & $10.60 \pm 1.68^{\mathrm{BC}}$ \\
\hline 60 seconds & $10.18 \pm 1.42^{\mathrm{Bb}}$ & $11.81 \pm 2.32^{\mathrm{Bb}}$ \\
\hline 90 seconds & $13.92 \pm 2.70^{\mathrm{Aa}}$ & $13.76 \pm 1.55^{\mathrm{Aa}}$ \\
\hline
\end{tabular}

Two-way ANOVA with Tukey. Different capital letters indicate difference between times, different lower letters indicate difference between concentrations $(p<0.05)$.

The failure pattern of the specimens is described in Table 2. Adhesive failures (Figure 3) were observed in $65.27 \%$ of the specimens, mixed cement failures (Figure 4) in $33.33 \%$ of the specimens and mixed ceramic failures (Figure 5) in $1.38 \%$ of the specimens. No cohesive failures were observed, either for cement or ceramics.
Table 2. Failure Pattern.

\begin{tabular}{l|c|c}
\hline & $\begin{array}{c}\text { Hydrofluoric } \\
\text { Acid 5\% }\end{array}$ & $\begin{array}{c}\text { Hydrofluoric } \\
\text { Acid 10\% }\end{array}$ \\
\hline Adhesive & 24 & 23 \\
\hline $\begin{array}{l}\text { Predominantly } \\
\text { Adhesive (Cement) }\end{array}$ & 12 & 12 \\
\hline $\begin{array}{l}\text { Predominantly Adhesive } \\
\text { (Ceramic) }\end{array}$ & 0 & 1 \\
\hline Cohesive & 0 & 0 \\
\hline
\end{tabular}

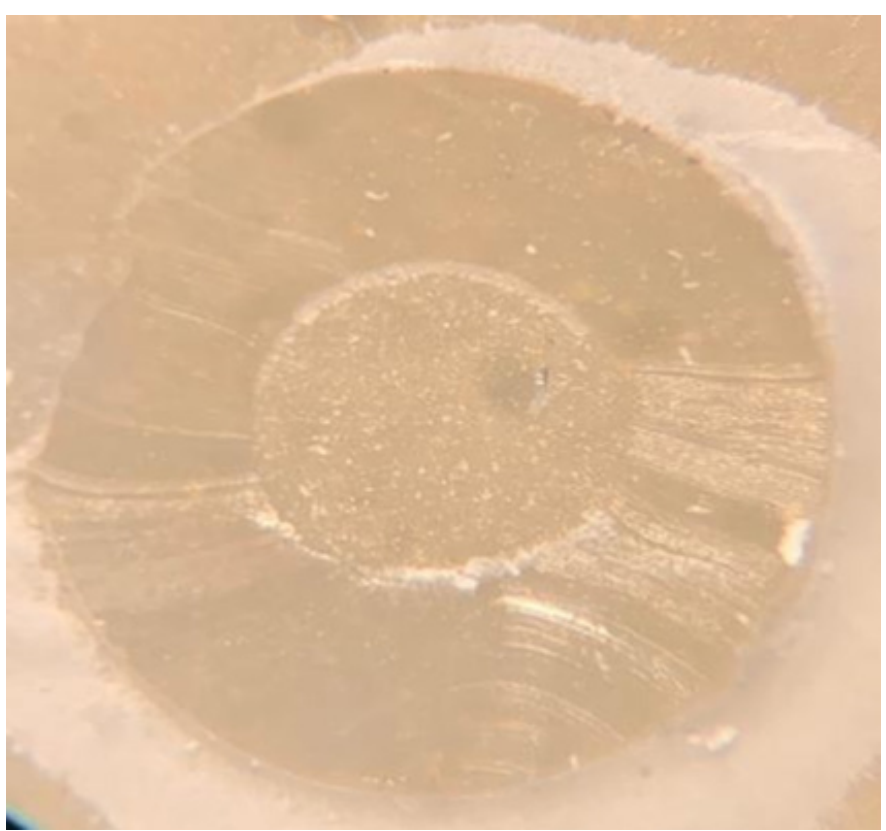

Figure 3. Adhesive Failure.

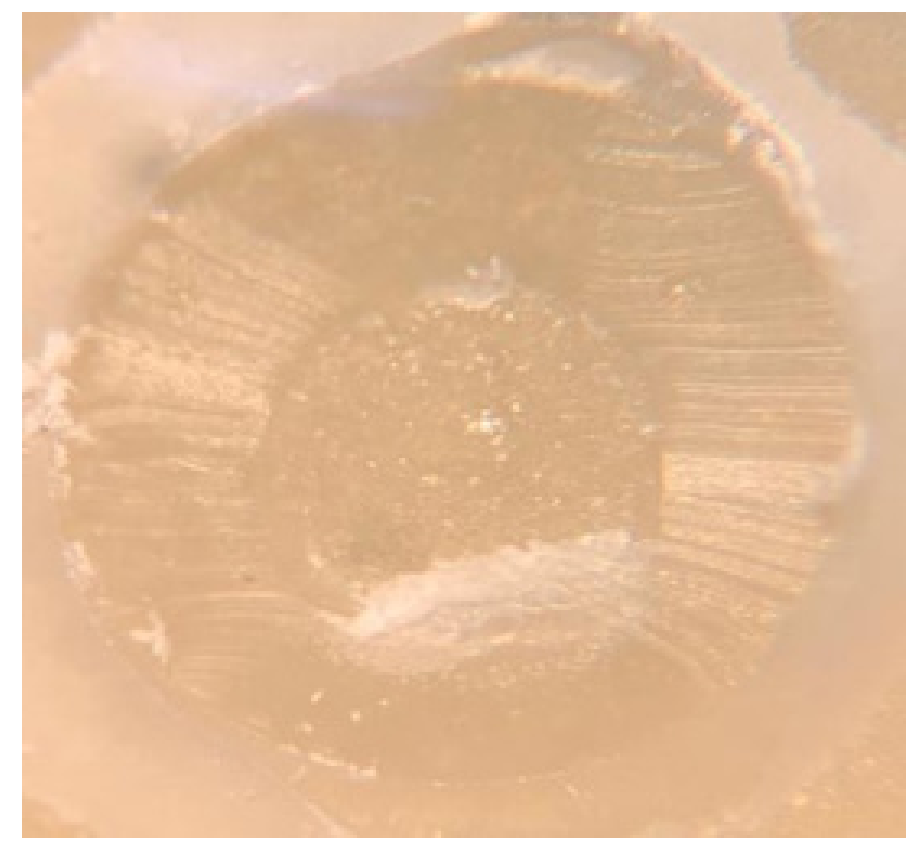

Figure 4. Predominantly Adhesive (cement). 


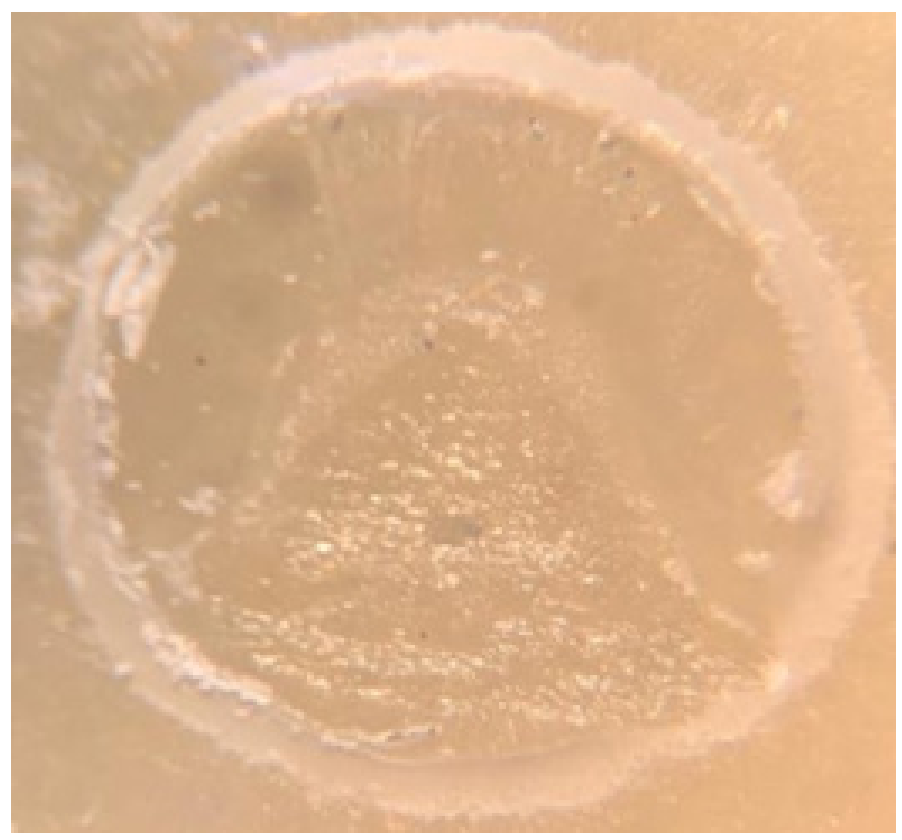

Figure 5. Predominantly Adhesive (ceramic).

\section{Discussion}

The present study observed that the result of bond strength between feldspathic ceramics and resin cement does not depend on the concentration of hydrofluoric acid, thus confirming the first null hypothesis.

Hydrofluoric acid reacts with silica in the glass matrix of feldspathic porcelain, forming free radicals called hexafluorsilicates, removed from the ceramic surface during washing under running water. Regardless of the acid concentration, irregularities on the ceramic surface occur due to the chemical reaction between the acid and silica, as shown by the study by Butze et al. ${ }^{3}$ and Guler et al. ${ }^{12}$

On the other hand, Sundfeld et al., ${ }^{13}$ tested different hydrofluoric acid concentrations (1,5 and 10\%) on a vitreous ceramic, and shows that the $10 \%$ concentration caused greater removal of the vitreous matrix when compared to the concentrations of 1 and 5\%. The ceramic used was lithium disilicate which, despite having a vitreous matrix, has a lower amount of silica in its composition than feldspar porcelain, thus requiring a higher concentration of $\mathrm{HF}$ to cause retention.

The results presented in the present study, the different concentrations obtained the same failure patterns within the same application time, suggesting that the bond strength between them was similar.

Regarding the variable time of application of hydrofluoric acid, this study showed that feldspathic ceramics, when submitted to application for a time of 80 seconds obtained higher bond strength than the times of 40 and 60 seconds, rejecting, therefore, the second null hypothesis.

Hydrofluoric acid reacts preferably with ceramic silica particles, creating retentive microchannels. Over time, the acid reacts with the vitreous matrix, causing a partial dissolution, increasing the formation of retentive channels, providing bond strength. In the present study, feldspathic ceramics was chosen, which has in its composition very high vitreous matrix, being more sensitive to the use of conditioning with hydrofluoric acid, therefore that when the conditioning time was increased, there was higher bond strength between resin cement and feldspathic ceramics.

Corroborating this study, Guler et al. ${ }^{12}$ evaluated the effect of different times (30s, 60s, 120s and 180s) of conditioning with hydrofluoric acid with a concentration of $9.6 \%$ in acidsensitive porcelain. The authors concluded that conditioning with HF for 120 s provided adequate bond strength between porcelain and cement.

In different circumstances, Zogheib et al. ${ }^{14}$ evaluated the conditioning with hydrofluoric acid with a concentration of $4.9 \%$ for four different times: $20 \mathrm{~s}, 60 \mathrm{~s}, 90 \mathrm{~s}$ and $180 \mathrm{~s}$. The highest values were found in the 90 s and 180s groups. Showing that the increase in the conditioning time affected the resistance of the lithium disilicate-based vitreous ceramic.

However, in Campos et al. ${ }^{4}$ study, when conditioning with $\mathrm{HF}$ at a concentration of $10 \%$ over 30 seconds and 2 minutes in a fluorapatite and feldspar-free leucite vitreus ceramic, it was found that the result of the bond strength between ceramic and resin cement was similar. This opposition is therefore given the ceramic used has quantity, size and type of inorganic molecules different from feldspathic ceramics, used in our research.

It is significant to mention that the excess of acid etching can generate a structural fragility in the ceramic piece, causing mechanical failures. Hence, it cannot be said that the solution for increasing the bond strength between resin cement and acid-sensitive ceramics is to increase the conditioning time without caution. ${ }^{15}$ Assessing the consequences of damage to the ceramic restoration is less harmful to obtain a failure in cementation than fracture in the porcelain, thus to lose the piece completely.

It is known that the use of HF in vitreous matrix porcelain provides the necessary surface roughness for micromechanical bonding. Although there was no significant difference using acid of different concentrations, according to the results, there was a difference in bond strength when the conditioning time was increased. ${ }^{16,17}$

Under the failure pattern analysis, $2 / 3$ of the specimens had adhesive-type failure and $1 / 3$ of the specimens had mixedtype failure. The specimens that showed mixed cement and mixed ceramic failures prove better bonding properties than specimens with adhesive failures, as stated by Lodi, Marks e Borba $^{18}$ in their study, which had similarity in the values of bond resistance between the groups in the shear test, but there was a difference in failure mode.The group that presented higher cement/ceramic resistance obtained more frequency 
of mixed and cohesive failures.

Restorations with this type of ceramic have multifactorial failure means and the evaluation methods presented provide partial data, since the oral cavity is a complex environment, being difficult to reproduce all its variables in a mechanical test with an in vitro research. It is important to emphasize that the technique for microshear testing is very sensitive and failures resulting from this can happen. From this study it becomes evident the need to maintain the precision of the time of acid application and further studies are needed to analyze with fractography tests to determine acceptable limits for the resistance of feldspathic ceramic through acid etching.

\section{Conclusions}

It can be concluded from this study that the different concentrations of hydrofluoric acid did not significantly influence the bond strength between ceramics/cement. In addition, the increase in conditioning time with hydrofluoric acid significantly affected the bond strength between ceramics and cement.

\section{References}

1. Della Bona A, Anusavice KJ. Microstructure, composition, and etching topography of dental ceramics. Int J Prosthodont. 2002;15(2):159-67.

2. Figueiredo-Pina CG, Patas N, Canhoto J, Cláudio R, Olhero SM, Serro AP, et al. Tribological behaviour of unveneered and veneered lithium disilicate dental material. J Mech Behav Biomed Mater. 2016;53:226-38.

3. Butze J, Marcondes ML, Burnett-Júnior LH, Spohr AM. Avaliação da topografia superficial de cerâmicas submetidas a diferentes tratamentos de superfície. Rev Stomatos. 2011;17(32):4-14.

4. Campos L, Telles M, Galhano GÁ, Camargo FP, Valandro LF, Mallmann A. Efeito do tempo de condicionamento da superfície cerâmica sobre a resistência adesiva entre uma cerâmica de fluorapatita e um cimento resinoso. Braz Dent Scienc. 2005;8(3):71-76.

5. Aurélio IL, Fraga S, Dorneles LS, Bottino MA, May LG. Extended glaze firing improves flexural strength of a glass ceramic. Dent Mater. 2015;31(12):e316-24. 6. Romão RM, Lopes GRS, Matos JDM, Lopes GRS, Vasconcelos JEL, Fontes NM. Causes of failures in ceramic veneers restorations: A literature review. Int J Adv Res. 2018;6(4):896-906.

7. Peixoto NM, Matos JDM, Andrade VC, Bottino MA, Zogheib LV. Evaluación de la resistenciade unión de brackets ortodónticos fijados a cerámica de disilicato de litio. Int J Odontostomat. 2019;13(2):207-218.

8. Amoroso AP, Ferreira MB, Torcato LB, Pellizzer EP, Mazaro JVQ, Gennari HF. Cerâmicas odontológicas: propriedades, indicações e considerações clínicas. Rev Odontol Arac. 2012;33(2):19-25.

9. Bader JD, Shugars DA. Summary review of the survival of single crowns. Gen Dent. 2009;57(1):74-81.

10. Bandeira AF, Lagustera CE, Sicoli EA, Mendonça MJ. Tratamento superficial de cerâmicas reforçadas in-ceram previamente aos procedimentos de cimentação adesiva - revisão de literatura. Revista RFO. 2008;13(1):80-85.

11. Bernardo RT, Obici AC, Sinhoreti MAC. Efeito da ativação química ou dual na microdureza knoop de cimentos resinosos. Rev Ciência Odont Bras. 2008;(11)4: 80-85.
12. Güler AU, Yilmaz F, Yenisey M, Güler E, Ural C. Effect of acid etching time and a self-etching adhesive on the shear bond strength of composite resin to porcelain. J Adhes Dent. 2006;8(1):21-5.

13. Sundfeld D, Palialol ARM, Fugolin APP, Ambrosano GMB, Correr-Sobrinho L, Martins LRM, Pfeifer CS. The effect of hydrofluoric acid and resin cement formulation on the bond strength to lithium disilicate ceramic. Braz Oral Res. 2018;24;32:e43.

14. Zogheib LV, Bona AD, Kimpara ET, McCabe JF. Effect of hydrofluoric acid etching duration on the roughness and flexural strength of a lithium disilicate-based glass ceramic. Braz Dent J. 2011;22(1):45-50.

15. Santos LR, Tunes RS, Silveira SRA, Freitas AP, Lisboa JAA, Lisboa MV. O ácido fluorídrico na resistência ao cisalhamento entre cerâmica feldspática e resina composta. Ver APCD. 2015;69(1):62-67.

16. Pereira ALC, Matuda LSA, Lima LG, Silva MFL, Morais-Sousa LK, Matos JDM, Vasconcelos JEL, Medeiros CR. Evaluation of thefluorescence of composite resins under an ultra violet light source. Int J Odontostomat. 2018;12(3):252261.

17. Gomes TN, Matos JDM, Vasconcelos JEL, Olivieri KAN, Brandt WC, Miranda ME. Effect of Different Photoiniciers of Experimental Adhesive Systems on Adhesive Interface Union Resistance. Int Arch of Med. 2018;11(26):1-12.

18. Lodi E, Marks F, Borba M. Efeito do tratamento de superfície na resistência de união entre porcelana e uma cerâmica à base de zircônia. Rev Cerâmica. 2017;63(366):238-43.

19. Panah FG, Rezai SM, Ahmadian L. The influence of ceramic surface treatments on the micro-shear bond strength of composite resin to IPS Empress 2. J Prosthodont. 2008;17(5):409-14.

20. Venturini AB, Prochnow C, Rambo D, Gundel A, Valandro LF. Effect of Hydrofluoric Acid Concentration on Resin Adhesion to a Feldspathic Ceramic. J Adhes Dent. 2015;17(4):313-20.

\section{Mini Curriculum and Author's Contribution}

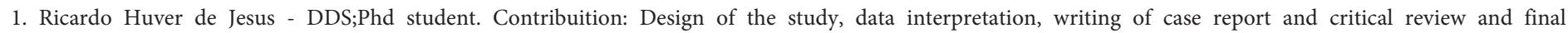
approval. ORCID: 0000-0002-2905-8068

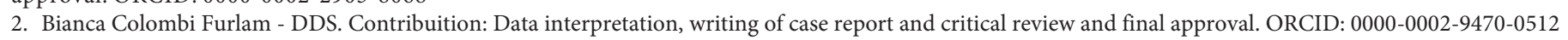

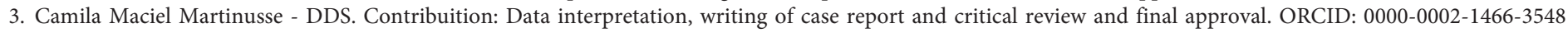

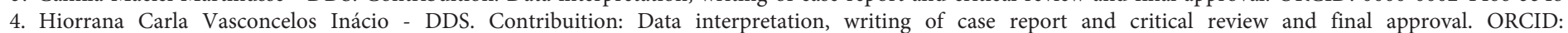
0000-0002-4729-3360

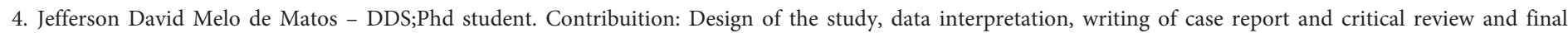
approval. ORCID: 0000-0003-4507-0785

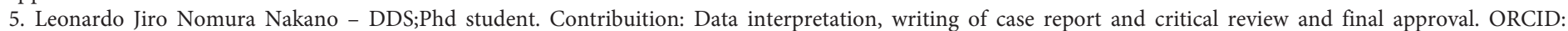
0000-0001-6786-862X

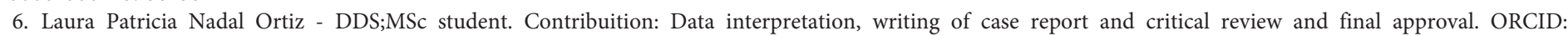
0000-0002-3577-0019

7. Marco Antonio Bottino - DDS;Phd. Contribuition: Writing of case report and critical review and final approval. ORCID: 0000-0003-0077-3161

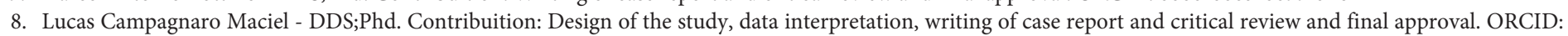
0000-0002-7687-4535 